\title{
THE ROLE OF CORPORATE CULTURE IN ECONOMIC DEVELOPMENT OF SMALL AND MEDIUM-SIZED ENTERPRISES
}

\author{
Silvia LORINCOVÁ (D ${ }^{*}$, Andrej MIKLOŠÍK (D)2 ${ }^{2}$, Miloš HITKA(D) 1 \\ ${ }^{1}$ Faculty of Wood Sciences and Technology, Technical University in Zvolen, Zvolen, Slovakia \\ ${ }^{2}$ Faculty of Management, Comenius University in Bratislava, Bratislava, Slovakia
}

Received 11 June 2021; accepted 05 September 2021; first published online 02 December 2021

\begin{abstract}
Achieving economic development of the enterprise is enabled by the efficient use of resources, efficient processes and, last but not least, a suitable corporate culture. Under the influence of a dynamically changing business environment, corporate culture is gaining in importance and justification. It needs to be monitored and evaluated together with "hard" business indicators. The research explores the key values that should be applied in corporate culture at the strategic level to support the economic development of small and medium-sized enterprises. The differences between small and medium-sized enterprises operating in the industrial sector in Slovakia are defined. As managers have a direct impact on the creation of corporate culture, their preferences regarding corporate culture are examined, using the methodology of Cameron and Quinn. The results of the research prove the preference for applying key values typical for a clan culture. Following the results, it is recommended managers to focus on supporting a clan culture that develops employees. It is the employees who create and build values, bring new, innovative ideas, and with their abilities and skills influence the performance, competitive advantage, economic development, and success of the entire enterprise as well as economic development of small and medium-sized enterprises.
\end{abstract}

Keywords: economic development, small and medium enterprises, corporate culture, strategy in corporate culture, the methodology of Cameron and Quinn, Tukey's HSD test, the clan corporate culture.

JEL Classification: F63, M14, O15.

\section{Introduction}

In the economic development of the economy, small and medium-sized enterprises (SMEs) have an irreplaceable place. They are considered to be the driving force of the economy. They contribute significantly to the increase of innovative activities of companies, to the flexible introduction of new products, to the creation of job opportunities (Lobos et al., 2020;

${ }^{\star}$ Corresponding author. E-mail: silvia.lorincova@tuzvo.sk

Copyright (c) 2021 The Author(s). Published by Vilnius Gediminas Technical University

This is an Open Access article distributed under the terms of the Creative Commons Attribution License (http://creativecommons. $\mathrm{org} / \mathrm{licenses} / \mathrm{by} / 4.0 /$ ), which permits unrestricted use, distribution, and reproduction in any medium, provided the original author and source are credited. 
Soewarno \& Tjahjadi, 2020). According to research of Anguelov and Angelova (2021), Hedvicakova and Kral (2021), and Tian et al. (2021) under the influence of increasing globalization and current trends, the demands on enterprises to create effective strategies to succeed in a highly competitive environment are growing. In order to achieve the overall success of the enterprise in a dynamically changing business environment, corporate culture is gaining in importance and justification because it is one of the factors that affects the performance, competitive advantage, economic development, and success of the entire enterprise (Vukasovic et al., 2021; Mohelska \& Sokolova, 2018). Corporate culture inevitably distinguishes one enterprise from another. It contributes to the willingness of employees to engage in the goals of the enterprise, to strengthen the initiative, to the quality of employees' work, to support their loyalty, to the responsibility towards the enterprise and to communicate effectively. It manifests subsequently in the economic development of the enterprise, its competitive advantage and overall success of the enterprise.

The term corporate culture originated in the 1960s, in the context of differences in corporate governance in the US (hierarchical type) and companies in Japan (clan tradition). Awareness of corporate culture has undoubtedly increased as a result of the growth of companies and their expansion abroad, where companies have found themselves in competition with other national cultures. When companies became aware of themselves as actors on the social scene, corporate culture became another aspect of business that needed to be monitored and evaluated, along with "hard" key performance indicators (Abdi et al., 2018). At present, corporate culture is an important element of corporate governance that influences enterprise operations (Kotter \& Heskett, 2011), its success (Vlaicu et al., 2019; Rezaei et al., 2016), competitiveness, social responsibility, innovation, and performance (Ha, 2020; Kraśnicka et al., 2018). The paper fills the gap in existing knowledge by identifying the key values that should be applied in corporate culture at the strategic level to support the economic development of SMEs in Slovakia.

\section{Literature review}

Corporate culture is an interdisciplinary concept that does not have a uniform definition, model or approach it. O'Reilly and Chatman (1996) argue that corporate culture can be seen as a set of norms and values that are widely shared and strongly held throughout the enterprise. According to Denison and Spreitzer (1991), corporate culture represents the basic values, opinions and assumptions that exist in a enterprise, patterns of behavior, that result from these common meanings and symbols that represent the connection between the assumptions, values, and behavior of enterprise members. Guiso et al. (2015) argue that corporate culture is a secret recipe for customer acquisition that revolves around teamwork, integrity, a spirit of humility and end-customer work. Stachová et al. (2015) considers corporate culture to be something like an enterprise's personality. It is a reflection of human dispositions, thinking and behavior of people in the enterprise. It affects the human consciousness and the subconscious and manifests itself in both (Guiso et al. 2015; Fernandez \& Fogli, 2009). It is a kind of active living phenomenon that concerns people's ideas and values influencing employee behavior (Chen et al., 2021; Teräväinen et al., 2018). Corporate culture is the 
implicit awareness of an enterprise that results from the behavior of the organization's members (Diedrich, 2017). Despite the differences in defining the essence of corporate culture, most authors incorporate certain common characteristics into its definitions. These include patterns of basic assumptions about employee behavior; values influencing the behavior of individuals, by drawing a line between what is permissible and inadmissible; the symbolism by which values are conveyed to employees of the enterprise.

Just as there is no uniformity in the definitions of corporate culture, there is no uniformity in its models and typologies. Kets De Vries and Miller (1984) examined the corporate culture in relation to the mental states of employees. Sonnenfeld (1988) dealt with human personality types. In the context of corporate culture, Miles et al. (1978) analyzed the adaptation of an enterprise to the indoor environment. In addition to these typologies, there are a number of others (e.g. Handy, 1985; Deal \& Kennedy, 1982; Harrison, 1972) that map the complexity of an enterprise's social environment and make it possible to understand the basic characteristics that distinguish companies.

We consider the typology of Cameron and Quinn (1999) as the most complex typology. It deals with corporate culture not only in relation to the degree of flexibility and control but also to the degree of internal and external environment (Naranjo-Valencia et al., 2016; Cameron \& Quinn, 1999; Quinn \& Rohrbaugh, 1983). This typology demonstrates the link between perceptions of corporate culture and corporate outcomes, such as corporate efficiency, development, sustainability, and overall success of the enterprise (Cameron \& Quinn, 1999). The typology defines four types of corporate culture (clan, adhocracy, market, and hierarchy) that correspond with the organizational theory and accurately captures the most important characteristics of each type of corporate culture.

Clan culture is similar to a family business, where companies are perceived more as extended families than economic entities. Emphasis is put on teamwork and employee engagement programs. Employees are invited to express their recommendations or suggestions and to participate in the important tasks. Clan corporate culture requires leaders to act as mentors who motivate employees to stimulate new knowledge and ideas (Andrianu, 2020; Hartnell et al., 2011). Adhocracy culture is characterized by a dynamic, entrepreneurial, and creative workplace. Businesses that practice this type of culture emphasize the need to be at the forefront of new knowledge, products, or services. This type of corporate culture assumes that employees will be ready for change. They must be open to experimentation and innovation. For success, leaders are expected to be visionary, innovative, and risk-oriented, with success defined as the creation of unique and authentic products (Al Issa, 2019). Another type is the market culture, which refers to a business oriented to results, profitability, competitiveness, and productivity (Hartnell et al., 2011). Leaders of companies with a market culture are strongly motivated, expect high performance, and emphasize victory and the achievement of measurable goals (Al Issa, 2019). Pragmatism is accepted as long as it leads to agreed results. An enterprise dominated by the hierarchy culture demonstrates a controlling style of management. The leader acts as a coordinator who monitors and organizes the tasks. A clear corporate structure, standardized rules and procedures, strict control and well-defined responsibilities prevail. The hierarchy culture offers stability that is maintained by a firm and strict rule (Al Issa, 2019). 
According to previous research, the clan culture is typical for the healthcare sector in Vietnam (Van Huy et al., 2020), hotel companies in Mexico (Ibarra-Michel et al., 2019) or Greek banks (Belias et al., 2015). Finnish construction industry professionals would embrace clan and adhocracy culture features to achieve a better level of construction efficiency (Teräväinen \& Junnonen, 2019). Market culture is applied at Kazakh universities, but clan culture is preferred in future (Dostiyarova, 2016). Hierarchy culture is typical for the construction industry in the Gulf Cooperation Council countries (Jaeger \& Adair, 2013), Turkish workplaces (Caliskan \& Zhu, 2019) or Polish public universities (Debski et al., 2020). In Indonesian SMEs, market culture prevails, and an adhocracy culture is preferred in the horizon of 5-10 years (Aziz \& Hiroshi, 2014). The presented research shows that there are differences in corporate culture not only from a geographical point of view but also from the point of view of the sectoral structure of companies. In addition, our many years of research confirm the fact that there are differences in corporate culture also in terms of enterprise size (Lorincova et al., 2016). The research described in this study expands knowledge about corporate culture in economic development of SMEs from the perspective of Slovak managers, who make decisions in regards to management, development, communication, and innovation processes. In the context of corporate culture, these managers have a direct impact on its creation. The aim of the paper is to identify the key values that should be applied in corporate culture to support the economic development of SMEs operating in Slovak industrial sector. Industrial SMEs have a strategic position in the sectoral structure in Slovakia. They provide job opportunities for the largest number of employees and significantly contribute to the creation of added value (Statistical Office of the Slovak Republic, 2018).

\section{Methodology}

During the period from 2016 to 2020, managers working at the middle and top level of management in SMEs from the industrial sector were addressed by the method of stratified selection. To determine the minimum range of sample selection, the Cochran formula was used to determine the ideal sample size with respect to the required level of accuracy, the required level of confidence, and the estimated proportion of the attribute present in the population:

$$
n_{0}=\frac{Z^{2} p q}{e^{2}}
$$

where: $z$ is critical value corresponding to the chosen reliability of the estimate; $p$ is the estimated proportion of the population which has the attribute in question; $q$ is $1-p ; e$ is the desired level of precision (i.e. the margin of error).

With a confidence level of $95 \%$, an accuracy of at least $5 \%$ and a critical value corresponding to the selected confidence of the estimate of 1.96 , in order to generalize the results, the minimum sample size is 385 respondents. The research involved 4,234 managers working in SMEs, which, given the conventions used in our research, met the criterion of a minimum sample size. Details of the research sample are presented in Table 1. 
Table 1. Research sample characteristics

\begin{tabular}{|c|c|c|c|c|c|}
\hline \multirow{2}{*}{ Age } & \multirow{2}{*}{\multicolumn{2}{|c|}{ Frequency }} & \multicolumn{2}{|c|}{ Size of enterprise } & \multirow{2}{*}{ Total } \\
\hline & & & Small & Medium & \\
\hline \multirow{4}{*}{$<30$} & \multicolumn{2}{|l|}{ Absolute frequency } & 398 & 406 & 804 \\
\hline & \multirow{3}{*}{ Relative frequency } & Column Frequency & $19.48 \%$ & $18.53 \%$ & \\
\hline & & Line Frequency & $49.50 \%$ & $50.50 \%$ & \\
\hline & & Total Frequency & $9.40 \%$ & $9.59 \%$ & $18.99 \%$ \\
\hline \multirow{4}{*}{$31-40$} & Absolute frequency & & 557 & 613 & 1,170 \\
\hline & \multirow{3}{*}{ Relative frequency } & Column Frequency & $27.26 \%$ & $27.98 \%$ & \\
\hline & & Line Frequency & $47.61 \%$ & $52.39 \%$ & \\
\hline & & Total Frequency & $13.16 \%$ & $14.48 \%$ & $27.63 \%$ \\
\hline \multirow{4}{*}{$41-50$} & \multicolumn{2}{|l|}{ Absolute frequency } & 534 & 594 & 1,128 \\
\hline & \multirow{3}{*}{ Relative frequency } & Column Frequency & $26.14 \%$ & $27.11 \%$ & \\
\hline & & Line Frequency & $47.34 \%$ & $52.66 \%$ & \\
\hline & & Total Frequency & $12.61 \%$ & $14.03 \%$ & $26.64 \%$ \\
\hline \multirow{4}{*}{$>50$} & \multicolumn{2}{|l|}{ Absolute frequency } & 554 & 578 & 1,132 \\
\hline & \multirow{3}{*}{ Relative frequency } & Column Frequency & $27.12 \%$ & $26.38 \%$ & \\
\hline & & Line Frequency & $48.94 \%$ & $51.06 \%$ & \\
\hline & & Total Frequency & $13.08 \%$ & $13.65 \%$ & $26.74 \%$ \\
\hline \multirow{2}{*}{ Total } & \multicolumn{2}{|l|}{ Absolute frequency } & 2,043 & 2,191 & 4,234 \\
\hline & \multicolumn{2}{|l|}{ Relative frequency } & $48.25 \%$ & $51.75 \%$ & \\
\hline
\end{tabular}

Note: Column Frequency - the share of the number of respondents according to the size of the enterprise; Line Frequency - the share of the number of respondents according to the age of the respondents; Total Frequency - the share of the number of respondents in the total number of respondents.

Managers were addressed by the method of sociological survey through questionnaires. In the first part of the questionnaire, managers were asked to identify their socio-demographic characteristics and the enterprise they work for. Subsequently, according to the methodology of Cameron and Quinn (1999), managers defined the preferred level of corporate culture using the six dimensions (dominant characteristics, organizational leadership, management of employees, organization glue, strategic emphases, and criteria of success). Within each dimension, they divided 100 points between four alternatives (alternative A corresponds to the clan culture; alternative $\mathrm{B}$ corresponds to the adhocracy culture; alternative $\mathrm{C}$ corresponds to the market culture; alternative D corresponds to the hierarchy culture) depending on their vision of how the enterprise should look like in the horizon of five to ten years. In the final phase, in accordance with the methodology of Cameron and Quinn (1999), the preferred type of corporate culture was defined at the strategic level by averaging the individual values.

The results obtained were further processed using statistical software RStudio. The methods of inductive statistics were used to test the significance of differences partially in individual dimensions in corporate culture as well as in the preferred type of corporate culture between SMEs. The researched issue was further expanded to differentiate the perception of corporate culture in terms of age group managers. The opinions of managers in the age 
categories up to 30 years, $31-40$ years, $41-50$ years, and over 50 years were examined. The research hypotheses were verified by means of interval estimates, Tukey's HSD test and the usual 5\% level of significance of the test:

1. It is assumed that in individual dimensions of corporate culture, key values typical for Alternative A will be preferred by managers of all age categories.

2. It is assumed that a clan corporate culture will be preferred by managers of all age categories.

\section{Results and discussion}

Each enterprise creates its own culture, which has its own specifics, originality, and uniqueness, and which support the performance, competitive advantage, economic development, and success of the entire enterprise. Nevertheless, many values of the corporate culture of one enterprise overlap with the values of the corporate culture of other companies. In the following section, key values in SMEs in six dimensions will be defined: dominant characteristics, organizational leadership, management of employees, organization glue, strategic emphases, and criteria of success.

\subsection{Dominant characteristics}

The results for the first dimension - dominant characteristics - are presented in Table 2. At a strategic level, SME managers of all ages prefer to apply the key values typical of Alternative A, according to which companies should be perceived as very personal places that resemble a multi-member family, where employees will often interact and share a lot of personal information and features. Despite the mutual consensus in respondents' opinions, statistical testing confirmed the existence of differences in the opinions of managers in all age categories in Alternative A. Statistically significant differences in corporate culture between SMEs are highlighted in Table 2.

\subsection{Organizational leadership}

Table 3 presents the results in the dimension of organizational leadership. The opinions of managers of small enterprises in terms of individual age categories are not clear. Although the Alternative A was perceived as the most important, also Alternative B and Alternative D scored relatively high. Based on these results, we can state that managers of small enterprises from the industrial sector prefer that management be based on a combination of key values from the alternatives A, B, and D. Managers of these companies should play the role of mentors (Alternative A), visionaries (Alternative B), and at the same time coordinators (Alternative D). Managers of medium-sized enterprises over the age of 31 prefer that the key values typical of Alternative $\mathrm{D}$ be clearly applied in management, and management should be based on organized coordination and monitoring. Statistical testing confirmed the existence of differences in the opinions of managers in all age categories in Alternative B, and Alternative D. Statistically significant differences in corporate culture between SMEs are presented in Table 3. 
Table 2. Testing the significance of differences in the dimension of dominant characteristics

\begin{tabular}{|c|c|c|c|c|c|c|c|c|c|c|}
\hline$\underset{4}{\infty}$ & 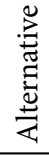 & 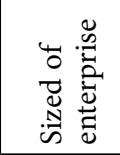 & 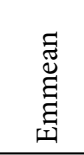 & 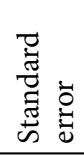 & 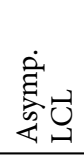 & 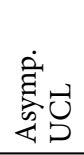 & 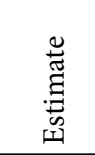 & 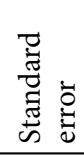 & 胥 & $\frac{\overrightarrow{0}}{\stackrel{2}{c}}$ \\
\hline \multirow{8}{*}{$<30$} & \multirow{2}{*}{ A } & Small & 0.380 & 0.011 & 0.358 & 0.401 & \multirow{2}{*}{0.034} & \multirow{2}{*}{0.008} & \multirow{2}{*}{4.187} & \multirow{2}{*}{$0.011^{\star}$} \\
\hline & & Medium & 0.346 & 0.011 & 0.325 & 0.367 & & & & \\
\hline & \multirow{2}{*}{ B } & Small & 0.224 & 0.008 & 0.208 & 0.241 & \multirow{2}{*}{0.009} & \multirow{2}{*}{0.006} & \multirow{2}{*}{1.448} & \multirow{2}{*}{1.000} \\
\hline & & Medium & 0.216 & 0.008 & 0.199 & 0.232 & & & & \\
\hline & \multirow{2}{*}{$\mathrm{C}$} & Small & 0.252 & 0.009 & 0.234 & 0.269 & \multirow{2}{*}{-0.013} & \multirow{2}{*}{0.007} & \multirow{2}{*}{-1.944} & \multirow{2}{*}{0.990} \\
\hline & & Medium & 0.265 & 0.009 & 0.247 & 0.283 & & & & \\
\hline & \multirow{2}{*}{$\mathrm{D}$} & Small & 0.236 & 0.009 & 0.219 & 0.253 & \multirow{2}{*}{-0.008} & \multirow{2}{*}{0.006} & \multirow{2}{*}{-1.234} & \multirow{2}{*}{1.000} \\
\hline & & Medium & 0.244 & 0.009 & 0.227 & 0.262 & & & & \\
\hline \multirow{8}{*}{$31-40$} & \multirow{2}{*}{ A } & Small & 0.381 & 0.009 & 0.364 & 0.398 & \multirow{2}{*}{0.034} & \multirow{2}{*}{0.008} & \multirow{2}{*}{4.188} & \multirow{2}{*}{$0.011^{\star}$} \\
\hline & & Medium & 0.347 & 0.008 & 0.331 & 0.363 & & & & \\
\hline & $\mathrm{P}$ & Small & 0.236 & 0.007 & 0.222 & 0.249 & 0009 & 0006 & 1448 & 1000 \\
\hline & D & Medium & 0.226 & 0.007 & 0.213 & 0.239 & 0.00 & 0.000 & 1.440 & 1.000 \\
\hline & $C$ & Small & 0.262 & 0.007 & 0.247 & 0.276 & $-0,014$ & 0007 & -1945 & 0990 \\
\hline & C & Medium & 0.275 & 0.007 & 0.261 & 0.290 & -0.014 & 0.001 & -1.945 & 0.990 \\
\hline & D & Small & 0.234 & 0.007 & 0.221 & 0.247 & - & 0,006 & 1234 & 1000 \\
\hline & $D$ & Medium & 0.242 & 0.007 & 0.228 & 0.256 & -0.000 & 0.000 & T & 1.000 \\
\hline & 4 & Small & 0.379 & 0.008 & 0.364 & 0.395 & 0034 & 0008 & 4191 & $0011^{*}$ \\
\hline & $\pi$ & Medium & 0.346 & 0.008 & 0.330 & 0.361 & 0.007 & 0.000 & T.1. & 0.011 \\
\hline & $\mathrm{B}$ & Small & 0.211 & 0.006 & 0.199 & 0.223 & 0008 & 0,006 & 1449 & 1000 \\
\hline & D & Medium & 0.203 & 0.006 & 0.191 & 0.214 & 0.000 & 0.000 & 1.14 & 1.000 \\
\hline $11-20$ & C & Small & 0.249 & 0.007 & 0.236 & 0.262 & 0 & 0,007 & 14 & 00090 \\
\hline & C & Medium & 0.262 & 0.007 & 0.248 & 0.276 & -0.013 & 0.007 & -1.944 & 0.990 \\
\hline & $\mathrm{D}$ & Small & 0.257 & 0.007 & 0.243 & 0.270 & -0008 & 0007 & -1234 & 1000 \\
\hline & $D$ & Medium & 0.265 & 0.007 & 0.251 & 0.279 & -0.008 & 0.007 & -1.234 & 1.000 \\
\hline & A & Small & 0.406 & 0.010 & 0.386 & 0.426 & 0,035 & 0.008 & 4.179 & $0.011^{*}$ \\
\hline & $\mathrm{A}$ & Medium & 0.371 & 0.009 & 0.353 & 0.389 & 0.035 & 0.000 & $4.1 / 9$ & 0.011 \\
\hline & B & Small & 0.201 & 0.007 & 0.188 & 0.215 & 0,008 & 0.006 & 1444 & 1000 \\
\hline$>50$ & 更 & Medium & 0.193 & 0.006 & 0.181 & 0.206 & 0.000 & 0.000 & 1.444 & 1.000 \\
\hline 00 & $C$ & Small & 0.250 & 0.008 & 0.234 & 0.266 & -0.013 & 0.007 & -1950 & 0.989 \\
\hline & C & Medium & 0.263 & 0.008 & 0.248 & 0.279 & -0.013 & 0.007 & -1.950 & 0.989 \\
\hline & $\mathrm{D}$ & Small & 0.230 & 0.008 & 0.215 & 0.245 & $-0,008$ & 0,006 & 36 & 1000 \\
\hline & 更 & Medium & 0.237 & 0.007 & 0.223 & 0.252 & 0.000 & 0.000 & 1.250 & 1.000 \\
\hline
\end{tabular}

Note: ${ }^{\star} \mathrm{p}<0.05$. 
Table 3. Testing the significance of differences in the dimension of organizational leadership

\begin{tabular}{|c|c|c|c|c|c|c|c|c|c|c|}
\hline$\underset{4}{8}$ & 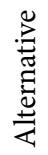 & 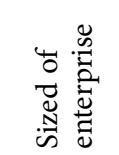 & 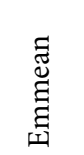 & 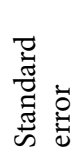 & 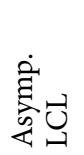 & 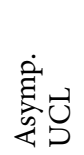 & 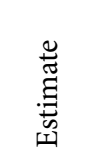 & 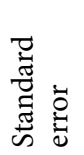 & 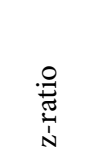 & $\frac{\bar{d}}{\stackrel{0}{0}}$ \\
\hline \multirow{8}{*}{$<30$} & \multirow{2}{*}{ A } & Small & 0.322 & 0.011 & 0.301 & 0.343 & \multirow{2}{*}{0.025} & \multirow{2}{*}{0.008} & \multirow{2}{*}{3.225} & \multirow{2}{*}{0.254} \\
\hline & & Medium & 0.297 & 0.010 & 0.278 & 0.317 & & & & \\
\hline & \multirow{2}{*}{ B } & Small & 0.299 & 0.010 & 0.279 & 0.319 & \multirow{2}{*}{0.039} & \multirow{2}{*}{0.007} & \multirow{2}{*}{5.336} & \multirow{2}{*}{$0.000^{\star}$} \\
\hline & & Medium & 0.260 & 0.009 & 0.242 & 0.279 & & & & \\
\hline & \multirow{2}{*}{$\mathrm{C}$} & Small & 0.276 & 0.009 & 0.259 & 0.293 & \multirow{2}{*}{0.010} & \multirow{2}{*}{0.006} & \multirow{2}{*}{1.860} & \multirow{2}{*}{0.995} \\
\hline & & Medium & 0.239 & 0.008 & 0.224 & 0.254 & & & & \\
\hline & \multirow{2}{*}{$\mathrm{D}$} & Small & 0.194 & 0.008 & 0.178 & 0.209 & \multirow{2}{*}{-0.050} & \multirow{2}{*}{0.007} & \multirow{2}{*}{-6.804} & \multirow{2}{*}{$0.000^{*}$} \\
\hline & & Medium & 0.183 & 0.007 & 0.169 & 0.198 & & & & \\
\hline \multirow{8}{*}{$31-40$} & \multirow{2}{*}{ A } & Small & 0.267 & 0.009 & 0.248 & 0.286 & \multirow{2}{*}{0.024} & \multirow{2}{*}{0.008} & \multirow{2}{*}{3.226} & \multirow{2}{*}{0.254} \\
\hline & & Medium & 0.317 & 0.011 & 0.297 & 0.338 & & & & \\
\hline & $\mathrm{B}$ & Small & 0.316 & 0.008 & 0.300 & 0.332 & 0038 & 0007 & 5344 & $\cap \cap \cap \Omega^{*}$ \\
\hline & $\mathrm{D}$ & Medium & 0.291 & 0.008 & 0.276 & 0.307 & 0.050 & 0.007 & 5.044 & 0.000 \\
\hline & & Small & 0.291 & 0.008 & 0.276 & 0.307 & & & & \\
\hline & $\mathrm{C}$ & Medium & 0.253 & 0.007 & 0.239 & 0.267 & 0.010 & 0.005 & 1.860 & 0.995 \\
\hline & $\mathrm{D}$ & Small & 0.180 & 0.006 & 0.169 & 0.191 & $=055$ & 0008 & -6853 & $\Omega \cap \cap \Omega^{*}$ \\
\hline & & Medium & 0.170 & 0.005 & 0.160 & 0.181 & -0.035 & 0.000 & -0.053 & 0.000 \\
\hline & & Small & 0.318 & 0.008 & 0.302 & 0.334 & & & & \\
\hline & A & Medium & 0.373 & 0.009 & 0.356 & 0.391 & 0.025 & 0.008 & 3.228 & 0.252 \\
\hline & $\mathrm{B}$ & Small & 0.331 & 0.008 & 0.316 & 0.347 & 0038 & 0007 & 5352 & $\Omega O \cap \Omega^{*}$ \\
\hline & D & Medium & 0.306 & 0.008 & 0.291 & 0.321 & 0.050 & 0.007 & 5.552 & 0.000 \\
\hline 4 & & Small & 0.286 & 0.007 & 0.272 & 0.301 & & & & \\
\hline & $\mathrm{C}$ & Medium & 0.249 & 0.007 & 0.236 & 0.262 & 0.010 & 0.005 & 1.861 & 0.995 \\
\hline & $\mathrm{D}$ & Small & 0.178 & 0.005 & 0.167 & 0.188 & $=054$ & 0008 & -6843 & $\Omega \cap \cap \Omega$ * \\
\hline & $D$ & Medium & 0.168 & 0.005 & 0.158 & 0.178 & -0.004 & 0.000 & $-0.04 J$ & 0.000 \\
\hline & 1 & Small & 0.303 & 0.007 & 0.288 & 0.318 & & (2) & 6 & 0 \\
\hline & $\mathrm{A}$ & Medium & 0.357 & 0.008 & 0.341 & 0.373 & 0.025 & 0.008 & 3.216 & 0.260 \\
\hline & $B$ & Small & 0.329 & 0.009 & 0.310 & 0.347 & 0.037 & 0007 & 5299 & $0000^{*}$ \\
\hline$>50$ & B & Medium & 0.304 & 0.009 & 0.287 & 0.321 & 0.037 & 0.007 & 5.299 & $0.000^{4}$ \\
\hline 300 & $C$ & Small & 0.160 & 0.006 & 0.149 & 0.172 & 0009 & 0005 & 1853 & 0995 \\
\hline & 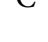 & Medium & 0.151 & 0.005 & 0.141 & 0.162 & 0.007 & $0.00 J$ & 1.030 & נינדים \\
\hline & D & Small & 0.323 & 0.009 & 0.305 & 0.341 & 5 & 008 & 25 & $00 \theta^{*}$ \\
\hline & D & Medium & 0.378 & 0.010 & 0.360 & 0.397 & -0.035 & 0.008 & -0.803 & 0.000 \\
\hline
\end{tabular}

Note: ${ }^{\star} \mathrm{p}<0.05$.

\subsection{Management of employees}

Details of the results of examining employee management are presented in Table 4. SMEs managers of all ages prefer to apply the key values typical of Alternative A. Following the results, it can be concluded that to support the economic development of small and medium- 
Table 4. Testing the significance of differences in the dimension of management of employees

\begin{tabular}{|c|c|c|c|c|c|c|c|c|c|c|}
\hline$\underset{4}{\infty}$ & 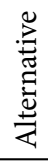 & 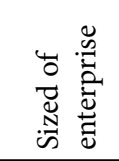 & 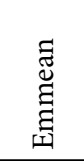 & 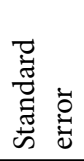 & 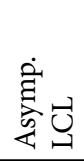 & 客足 & 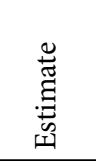 & 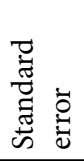 & 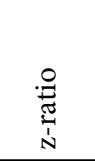 & $\frac{\overrightarrow{0}}{\frac{0}{1}}$ \\
\hline \multirow{8}{*}{$<30$} & \multirow{2}{*}{ A } & Small & 0.432 & 0.011 & 0.409 & 0.454 & \multirow{2}{*}{0.014} & \multirow{2}{*}{0.008} & \multirow{2}{*}{1.720} & \multirow{2}{*}{0.999} \\
\hline & & Medium & 0.417 & 0.011 & 0.395 & 0.439 & & & & \\
\hline & \multirow{2}{*}{ B } & Small & 0.215 & 0.008 & 0.199 & 0.231 & \multirow{2}{*}{0.023} & \multirow{2}{*}{0.006} & \multirow{2}{*}{4.053} & \multirow{2}{*}{$0.019^{*}$} \\
\hline & & Medium & 0.191 & 0.008 & 0.177 & 0.206 & & & & \\
\hline & \multirow{2}{*}{$\mathrm{C}$} & Small & 0.176 & 0.007 & 0.162 & 0.190 & \multirow{2}{*}{0.011} & \multirow{2}{*}{0.005} & \multirow{2}{*}{2.178} & \multirow{2}{*}{0.953} \\
\hline & & Medium & 0.165 & 0.007 & 0.152 & 0.179 & & & & \\
\hline & \multirow{2}{*}{$\mathrm{D}$} & Small & 0.270 & 0.009 & 0.252 & 0.288 & \multirow{2}{*}{-0.021} & \multirow{2}{*}{0.007} & \multirow{2}{*}{-2.991} & \multirow{2}{*}{0.420} \\
\hline & & Medium & 0.291 & 0.010 & 0.272 & 0.310 & & & & \\
\hline \multirow{8}{*}{$31-40$} & \multirow{2}{*}{ A } & Small & 0.426 & 0.009 & 0.409 & 0.443 & \multirow{2}{*}{0.014} & \multirow{2}{*}{0.008} & \multirow{2}{*}{1.720} & \multirow{2}{*}{0.999} \\
\hline & & Medium & 0.412 & 0.009 & 0.395 & 0.429 & & & & \\
\hline & $\mathrm{P}$ & Small & 0.221 & 0.006 & 0.208 & 0.233 & 0024 & 000 & 1061 & $0018 *$ \\
\hline & $D$ & Medium & 0.197 & 0.006 & 0.185 & 0.209 & 0.024 & 0.000 & 4.061 & 0.018 \\
\hline & $C$ & Small & 0.168 & 0.005 & 0.158 & 0.179 & 0011 & 0005 & 2178 & 0953 \\
\hline & C & Medium & 0.157 & 0.005 & 0.147 & 0.167 & 0.011 & $0.00 J$ & 2.170 & 0.935 \\
\hline & D & Small & 0.286 & 0.008 & 0.271 & 0.301 & & & & \\
\hline & D & Medium & 0.308 & 0.008 & 0.293 & 0.323 & -0.022 & 0.007 & -2.996 & 0.416 \\
\hline & A & Small & 0.454 & 0.008 & 0.437 & 0.470 & 0015 & 0008 & 1720 & 0999 \\
\hline & $\mathrm{A}$ & Medium & 0.439 & 0.008 & 0.423 & 0.456 & 0.010 & 0.000 & 1.720 & 0.999 \\
\hline & $\mathrm{P}$ & Small & 0.214 & 0.006 & 0.202 & 0.226 & בר & 0,00 & 4067 & $0018 *$ \\
\hline & D & Medium & 0.191 & 0.006 & 0.180 & 0.202 & 0.023 & 0.000 & $4.06 /$ & 0.018 \\
\hline $41-30$ & $C$ & Small & 0.155 & 0.005 & 0.146 & 0.164 & 0010 & 0005 & 2180 & 0.953 \\
\hline & C & Medium & 0.145 & 0.005 & 0.136 & 0.154 & 0.010 & 0.005 & 2.100 & 0.935 \\
\hline & $\mathrm{D}$ & Small & 0.283 & 0.007 & 0.269 & 0.297 & & & & \\
\hline & D & Medium & 0.305 & 0.007 & 0.290 & 0.320 & -0.022 & 0.007 & -2.994 & 0.418 \\
\hline & A & Small & 0.498 & 0.010 & 0.477 & 0.518 & 0015 & 0009 & 1720 & 0999 \\
\hline & $\mathrm{A}$ & Medium & 0.483 & 0.010 & 0.464 & 0.502 & 0.010 & 0.007 & 1.720 & 0.999 \\
\hline & $B$ & Small & 0.200 & 0.007 & 0.186 & 0.213 & 0.022 & 0005 & 4028 & $0,020^{*}$ \\
\hline$>50$ & D & Medium & 0.178 & 0.006 & 0.166 & 0.189 & 0.022 & 0.005 & 4.020 & 0.020 \\
\hline$>50$ & $C$ & Small & 0.145 & 0.005 & 0.134 & 0.155 & 0009 & 0004 & 2168 & 0956 \\
\hline & 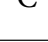 & Medium & 0.135 & 0.005 & 0.126 & 0.145 & 0.003 & 0.004 & 2.100 & 0.750 \\
\hline & D & Small & 0.280 & 0.008 & 0.263 & 0.296 & ר?חת & 007 & 4 & 410 \\
\hline & D & Medium & 0.301 & 0.008 & 0.285 & 0.318 & -0.022 & 0.007 & -5.004 & 0.410 \\
\hline
\end{tabular}

Note: ${ }^{*} \mathrm{p}<0.05$.

sized enterprises, employee management should focus on teamwork and collaboration. More statistically significant differences were confirmed in the opinions of managers in all age categories in Alternative B. 


\subsection{Organization glue}

Alternative A achieved the highest rating in the fourth examined dimension of organization glue (Table 5). Managers of all ages working in SMEs from the industrial sector are of the opinion that employees should be united by loyalty and mutual trust to support the economic development of small and medium-sized enterprises. Employees should be highly committed to their enterprise. Following the results presented in Table 5, it can be stated, that despite the mutual consensus in respondents' opinions, statistical testing confirmed the existence of differences in the opinions of managers in all age categories in mainly in Alternative A, and Alternative D.

Table 5. Testing the significance of differences in the dimension of organization glue

\begin{tabular}{|c|c|c|c|c|c|c|c|c|c|c|}
\hline 品 & 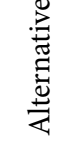 & 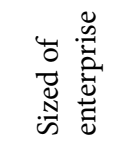 & 芯 & 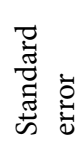 & 客 & 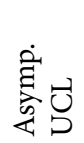 & 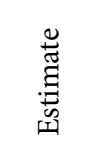 & 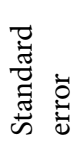 & 苞 & $\frac{\overrightarrow{0}}{\stackrel{0}{\vdots}}$ \\
\hline \multirow{8}{*}{$<30$} & \multirow{2}{*}{ A } & Small & 0.359 & 0.011 & 0.339 & 0.380 & \multirow{2}{*}{0.044} & \multirow{2}{*}{0.008} & \multirow{2}{*}{5.709} & \multirow{2}{*}{$0.000^{*}$} \\
\hline & & Medium & 0.316 & 0.010 & 0.296 & 0.336 & & & & \\
\hline & \multirow{2}{*}{ B } & Small & 0.240 & 0.009 & 0.223 & 0.257 & \multirow{2}{*}{0.002} & \multirow{2}{*}{0.006} & \multirow{2}{*}{0.327} & \multirow{2}{*}{1.000} \\
\hline & & Medium & 0.237 & 0.009 & 0.221 & 0.254 & & & & \\
\hline & \multirow{2}{*}{ C } & Small & 0.229 & 0.008 & 0.213 & 0.246 & \multirow{2}{*}{-0.007} & \multirow{2}{*}{0.006} & \multirow{2}{*}{-1.137} & \multirow{2}{*}{1.000} \\
\hline & & Medium & 0.237 & 0.009 & 0.220 & 0.253 & & & & \\
\hline & \multirow{2}{*}{ D } & Small & 0.227 & 0.008 & 0.210 & 0.243 & \multirow{2}{*}{-0.028} & \multirow{2}{*}{0.006} & \multirow{2}{*}{-4.371} & \multirow{2}{*}{$0.005^{\star}$} \\
\hline & & Medium & 0.255 & 0.009 & 0.237 & 0.272 & & & & \\
\hline \multirow{8}{*}{$31-40$} & \multirow{2}{*}{ A } & Small & 0.390 & 0.009 & 0.373 & 0.406 & \multirow{2}{*}{0.045} & \multirow{2}{*}{0.008} & \multirow{2}{*}{5.717} & \multirow{2}{*}{$0.000^{*}$} \\
\hline & & Medium & 0.344 & 0.008 & 0.328 & 0.360 & & & & \\
\hline & $\mathrm{B}$ & Small & 0.236 & 0.007 & 0.223 & 0.249 & ל & 0006 & 0227 & 100 \\
\hline & $\mathrm{D}$ & Medium & 0.234 & 0.007 & 0.221 & 0.247 & 0.002 & 0.006 & 0.021 & 1.000 \\
\hline & $C$ & Small & 0.250 & 0.007 & 0.236 & 0.263 & _ & 0007 & -138 & $10 \Omega 0$ \\
\hline & C & Medium & 0.257 & 0.007 & 0.243 & 0.271 & -0.008 & 0.007 & -1.130 & 1.000 \\
\hline & D & Small & 0.234 & 0.007 & 0.220 & 0.247 & & 0007 & 4385 & $0005^{\star}$ \\
\hline & D & Medium & 0.262 & 0.007 & 0.248 & 0.276 & -0.029 & 0.007 & 5 & 0.003 \\
\hline & A & Small & 0.396 & 0.008 & 0.380 & 0.412 & 0046 & 0008 & 5727 & $0 \cap 0 \cap 0$ \\
\hline & ${ }^{A}$ & Medium & 0.350 & 0.008 & 0.335 & 0.366 & 0.040 & 0.000 & 0.122 & 0.000 \\
\hline & $B$ & Small & 0.226 & 0.006 & 0.214 & 0.238 & 0.002 & 0.006 & 0327 & 1000 \\
\hline $41-5$ & & Medium & 0.224 & 0.006 & 0.212 & 0.236 & 0.002 & 0.000 & 0.021 & 1.000 \\
\hline $41-30$ & C & Small & 0.252 & 0.007 & 0.239 & 0.264 & 08 & 0007 & 137 & $100 \Omega$ \\
\hline & 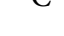 & Medium & 0.259 & 0.007 & 0.246 & 0.272 & -0.000 & 0.007 & -1.107 & 1.000 \\
\hline & $\mathrm{D}$ & Small & 0.231 & 0.006 & 0.219 & 0.243 & $10 \quad-5$ & 0006 & 89 & $0005 *$ \\
\hline & D & Medium & 0.259 & 0.007 & 0.246 & 0.272 & $-0.0<0$ & 0.000 & f.JO2 & 0.003 \\
\hline & $A$ & Small & 0.416 & 0.010 & 0.396 & 0.435 & 0046 & 0008 & 5701 & $0 \cap \cap \Omega^{*}$ \\
\hline & 1 & Medium & 0.369 & 0.009 & 0.351 & 0.387 & & & & \\
\hline & $B_{1}$ & Small & 0.224 & 0.007 & 0.209 & 0.238 & ? & 0006 & 0327 & 1000 \\
\hline$>50$ & & Medium & 0.222 & 0.007 & 0.208 & 0.235 & 0.002 & 0.000 & 0.021 & 1.000 \\
\hline (3) & C & Small & 0.241 & 0.008 & 0.226 & 0.257 & -0.007 & 0.006 & -1.139 & 1000 \\
\hline & 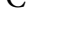 & Medium & 0.249 & 0.008 & 0.234 & 0.264 & -0.007 & 0.000 & 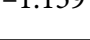 & 1.000 \\
\hline & D & Small & 0.220 & 0.007 & 0.205 & 0.234 & 7 & 0006 & & 0004 * \\
\hline & D & Medium & 0.247 & 0.007 & 0.232 & 0.262 & -0.027 & 0.000 & -4.400 & 0.004 \\
\hline
\end{tabular}

Note: ${ }^{*} \mathrm{p}<0.05$. 


\subsection{Strategic emphases}

Following the research results presented in Table 6, it can be stated that in the dimension of strategic emphases the highest rating was achieved by alternative A. According to SMEs managers of all ages, corporate strategies should focus on the key values typical for the highest rated Alternative A. Business strategies should focus on human development, high trust, openness, and cooperation which will support the economic development of the enterprise. Despite the mutual consensus in respondents' opinions, statistical testing confirmed the existence of differences in the opinions of managers in all age categories in Alternative A, and Alternative D in the dimension of strategic emphases as well.

Table 6. Testing the significance of differences in the dimension of strategic emphases

\begin{tabular}{|c|c|c|c|c|c|c|c|c|c|c|}
\hline$\underset{\pi}{\infty}$ & 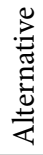 & 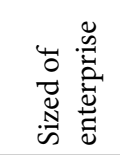 & 芯 & 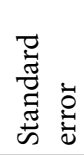 & 官 & 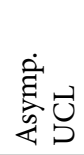 & 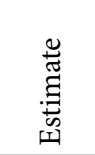 & 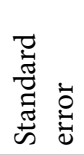 & 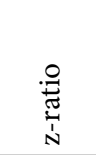 & $\frac{\overrightarrow{0}}{\stackrel{0}{\Delta}}$ \\
\hline \multirow{8}{*}{$<30$} & \multirow{2}{*}{ A } & Small & 0.381 & 0.011 & 0.360 & 0.402 & \multirow{2}{*}{0.059} & \multirow{2}{*}{0.008} & \multirow{2}{*}{7.630} & \multirow{2}{*}{$0.000^{\star}$} \\
\hline & & Medium & 0.323 & 0.010 & 0.303 & 0.342 & & & & \\
\hline & \multirow{2}{*}{ B } & Small & 0.245 & 0.009 & 0.228 & 0.262 & \multirow{2}{*}{0.006} & \multirow{2}{*}{0.006} & \multirow{2}{*}{0.944} & \multirow{2}{*}{1.000} \\
\hline & & Medium & 0.239 & 0.009 & 0.222 & 0.256 & & & & \\
\hline & \multirow{2}{*}{$\mathrm{C}$} & Small & 0.222 & 0.008 & 0.206 & 0.238 & \multirow{2}{*}{-0.007} & \multirow{2}{*}{0.006} & \multirow[b]{2}{*}{-1.131} & \multirow{2}{*}{1.000} \\
\hline & & Medium & 0.229 & 0.008 & 0.213 & 0.246 & & & & \\
\hline & \multirow{2}{*}{$\mathrm{D}$} & Small & 0.233 & 0.008 & 0.217 & 0.250 & \multirow{2}{*}{-0.036} & \multirow{2}{*}{0.007} & \multirow{2}{*}{-5.545} & \multirow{2}{*}{$0.000^{*}$} \\
\hline & & Medium & 0.270 & 0.009 & 0.252 & 0.288 & & & & \\
\hline \multirow{8}{*}{$31-40$} & \multirow{2}{*}{ A } & Small & 0.395 & 0.008 & 0.379 & 0.412 & \multirow{2}{*}{0.060} & \multirow{2}{*}{0.008} & \multirow{2}{*}{7.644} & \multirow{2}{*}{$0.000^{\star}$} \\
\hline & & Medium & 0.336 & 0.008 & 0.320 & 0.351 & & & & \\
\hline & $\mathrm{P}$ & Small & 0.254 & 0.007 & 0.240 & 0.267 & 0006 & 0007 & 0044 & 1000 \\
\hline & D & Medium & 0.247 & 0.007 & 0.234 & 0.261 & 0.000 & 0.007 & 0.944 & 1.000 \\
\hline & $C$ & Small & 0.227 & 0.006 & 0.215 & 0.240 & 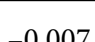 & 0006 & 131 & 1000 \\
\hline & C & Medium & 0.234 & 0.007 & 0.221 & 0.247 & -0.007 & 0.000 & -1.131 & 1.000 \\
\hline & $\mathrm{D}$ & Small & 0.217 & 0.006 & 0.205 & 0.230 & 0035 & 0006 & 5565 & $0 \Omega 0 \Omega *$ \\
\hline & D & Medium & 0.252 & 0.007 & 0.238 & 0.266 & -0.035 & 0.000 & -5.005 & 0.000 \\
\hline & 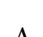 & Small & 0.401 & 0.008 & 0.385 & 0.417 & 0060 & 0000 & 7654 & 0 OnOA \\
\hline & A & Medium & 0.341 & 0.008 & 0.326 & 0.356 & 0.060 & 0.008 & 1.654 & $0.000^{\circ}$ \\
\hline & $\mathrm{B}$ & Small & 0.234 & 0.006 & 0.222 & 0.247 & 0006 & 0006 & 0945 & 1000 \\
\hline 4 & D & Medium & 0.229 & 0.006 & 0.216 & 0.241 & & 0.000 & 45 & 1.000 \\
\hline $41-50$ & C & Small & 0.210 & 0.006 & 0.199 & 0.222 & -0.007 & 0.006 & -1.131 & 1.000 \\
\hline & C & Medium & 0.217 & 0.006 & 0.205 & 0.229 & -0.007 & 0.006 & -1.131 & 1.000 \\
\hline & D & Small & 0.244 & 0.006 & 0.231 & 0.256 & 0027 & 0007 & 5567 & 0 OPOA \\
\hline & D & Medium & 0.281 & 0.007 & 0.267 & 0.295 & -0.037 & 0.007 & $-5.56 /$ & 0.000 \\
\hline & A & Small & 0.392 & 0.010 & 0.373 & 0.411 & & 0008 & & $20^{*}$ \\
\hline & A & Medium & 0.333 & 0.009 & 0.316 & 0.349 & & 0.008 & & 0 \\
\hline & B & Small & 0.249 & 0.008 & 0.233 & 0.264 & 0.006 & 0.006 & 0.943 & 1.000 \\
\hline$>50$ & B & Medium & 0.243 & 0.007 & 0.228 & 0.257 & 0.006 & 0.000 & 0.943 & 1.000 \\
\hline$>30$ & C & Small & 0.222 & 0.007 & 0.207 & 0.236 & - 0007 & 0006 & -1133 & 1000 \\
\hline & C & Medium & 0.229 & 0.007 & 0.215 & 0.242 & -0.007 & & -1.153 & 1.000 \\
\hline & D & Small & 0.233 & 0.008 & 0.219 & 0.248 & -0.036 & 0.006 & -5.601 & \\
\hline & D & Medium & 0.270 & 0.008 & 0.254 & 0.285 & & & & \\
\hline
\end{tabular}

Note: ${ }^{\star} \mathrm{p}<0.05$. 


\subsection{Criteria of success}

The results achieved in the dimension of success criteria are presented in Table 7. Managers of all ages working in SMEs from the industrial sector agreed and assigned the highest values to Alternative A. The SMEs should define success on the basis of development of human resources, teamwork, employee commitment, and care for people. Despite the mutual consensus in respondents' opinions, in the dimension of criteria of success, statistically significant differences were confirmed in the opinions of managers in all age categories in Alternative D.

Table 7. Testing the significance of differences in the dimension of criteria of success

\begin{tabular}{|c|c|c|c|c|c|c|c|c|c|c|}
\hline$\stackrel{8}{4}$ & 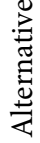 & 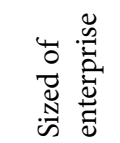 & 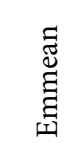 & 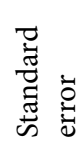 & 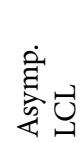 & 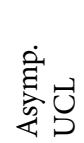 & 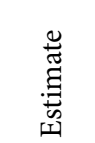 & 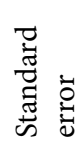 & 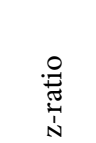 & $\frac{\overrightarrow{0}}{\stackrel{0}{0}}$ \\
\hline \multirow{8}{*}{$<30$} & \multirow{2}{*}{ A } & Small & 0.379 & 0.011 & 0.357 & 0.401 & \multirow{2}{*}{0.027} & \multirow{2}{*}{0.008} & \multirow{2}{*}{3.319} & \multirow{2}{*}{0.201} \\
\hline & & Medium & 0.352 & 0.011 & 0.331 & 0.373 & & & & \\
\hline & \multirow{2}{*}{ B } & Small & 0.243 & 0.009 & 0.225 & 0.260 & \multirow{2}{*}{0.020} & \multirow{2}{*}{0.006} & \multirow{2}{*}{3.202} & \multirow{2}{*}{0.268} \\
\hline & & Medium & 0.222 & 0.008 & 0.206 & 0.239 & & & & \\
\hline & \multirow{2}{*}{$\mathrm{C}$} & Small & 0.214 & 0.008 & 0.197 & 0.230 & \multirow{2}{*}{0.010} & \multirow{2}{*}{0.006} & \multirow{2}{*}{1.762} & \multirow{2}{*}{0.998} \\
\hline & & Medium & 0.203 & 0.008 & 0.188 & 0.219 & & & & \\
\hline & \multirow{2}{*}{ D } & Small & 0.235 & 0.009 & 0.218 & 0.252 & \multirow{2}{*}{-0.054} & \multirow{2}{*}{0.007} & \multirow{2}{*}{-7.700} & \multirow{2}{*}{$0.000^{*}$} \\
\hline & & Medium & 0.289 & 0.010 & 0.270 & 0.309 & & & & \\
\hline \multirow{8}{*}{$31-40$} & \multirow{2}{*}{ A } & Small & 0.418 & 0.009 & 0.401 & 0.436 & \multirow{2}{*}{0.028} & \multirow{2}{*}{0.008} & \multirow{2}{*}{3.320} & \multirow{2}{*}{0.201} \\
\hline & & Medium & 0.390 & 0.009 & 0.373 & 0.408 & & & & \\
\hline & $\mathrm{P}$ & Small & 0.241 & 0.007 & 0.228 & 0.255 & הכ0 & 0006 & 2204 & 0267 \\
\hline & D & Medium & 0.221 & 0.007 & 0.208 & 0.234 & 0.020 & 0.000 & 3.204 & $0.20 /$ \\
\hline & $C_{1}$ & Small & 0.220 & 0.007 & 0.207 & 0.233 & & 0006 & 1762 & 0000 \\
\hline & 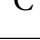 & Medium & 0.209 & 0.006 & 0.197 & 0.222 & 0.011 & 0.000 & 1.703 & 0.990 \\
\hline & $\mathrm{D}$ & Small & 0.234 & 0.007 & 0.220 & 0.247 & & 0007 & 7757 & $C_{1}$ \\
\hline & D & Medium & 0.287 & 0.008 & 0.272 & 0.302 & -0.035 & 0.007 & -1.737 & 0.000 \\
\hline & $A$ & Small & 0.442 & 0.009 & 0.425 & 0.459 & 0078 & 0,000 & 2321 & \\
\hline & A & Medium & 0.414 & 0.009 & 0.397 & 0.430 & 0.028 & 0.009 & 3.321 & 0.200 \\
\hline & $\mathrm{D}$ & Small & 0.227 & 0.006 & 0.215 & 0.239 & הרחת & 0006 & 2007 & 02 \\
\hline $41-5$ & & Medium & 0.208 & 0.006 & 0.196 & 0.219 & & & & \\
\hline $41-50$ & $C$ & Small & 0.211 & 0.006 & 0.200 & 0.223 & 0010 & 0006 & 1761 & 0000 \\
\hline & $C$ & Medium & 0.201 & 0.006 & 0.190 & 0.213 & 0.010 & 0.000 & 1.704 & 0.990 \\
\hline & $\mathrm{D}$ & Small & 0.229 & 0.006 & 0.216 & 0.241 & 0 & 0007 & & 0000 * \\
\hline & D & Medium & 0.281 & 0.007 & 0.267 & 0.296 & -0.053 & 0.007 & $-1.74 /$ & 0.000 \\
\hline & A & Small & 0.460 & 0.010 & 0.440 & 0.481 & 0000 & 0009 & 3317 & בתב ח \\
\hline & & Medium & 0.432 & 0.010 & 0.413 & 0.451 & 0.029 & & J.J17 & \\
\hline & $B_{1}$ & Small & 0.237 & 0.008 & 0.222 & 0.252 & 0 & 0006 & 3188 & 0277 \\
\hline$>50$ & D & Medium & 0.217 & 0.007 & 0.203 & 0.231 & $0.0 \angle 0$ & 0.006 & 3.188 & $0.27 /$ \\
\hline & C & Small & 0.197 & 0.007 & 0.183 & 0.210 & 0 & 0006 & 1757 & 0.998 \\
\hline & $C$ & Medium & 0.187 & 0.006 & 0.174 & 0.199 & 0.010 & 0.000 & $1.75 /$ & 0.990 \\
\hline & $\mathrm{D}$ & Small & 0.227 & 0.008 & 0.212 & 0.242 & 0052 & 0007 & 7810 & 0000 * \\
\hline & D & Medium & 0.279 & 0.008 & 0.263 & 0.296 & -0.052 & 0.007 & -7.010 & 0.000 \\
\hline
\end{tabular}

Note: ${ }^{\star} \mathrm{p}<0.05$. 


\subsection{Preferred type of corporate culture in SMEs}

In the final phase, in accordance with the methodology of Cameron and Quinn (1999), the preferred type of corporate culture was defined at the strategic level by averaging the individual values. The results presented in Table 8 show that managers of all ages working in Slovak SMEs from the industrial sector prefer the application of key values typical for the clan culture. Managers are of the opinion that emphasis should be placed on flexibility, power, and family relationships within the enterprise. Teamwork should be crucial. Decision-making

Table 8. Testing the significance of differences in the preferred type of corporate culture

\begin{tabular}{|c|c|c|c|c|c|c|c|c|c|c|}
\hline$\underset{4}{\square}$ & 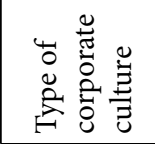 & 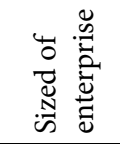 & 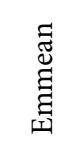 & 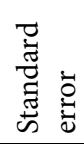 & 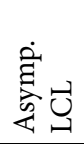 & 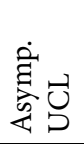 & 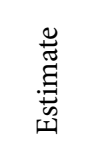 & 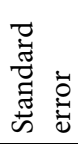 & 莺 & $\frac{\overrightarrow{0}}{\stackrel{0}{0}}$ \\
\hline \multirow{8}{*}{$<30$} & \multirow{2}{*}{ Clan } & Small & 0.364 & 0.006 & 0.352 & 0.377 & \multirow{2}{*}{0.031} & \multirow{2}{*}{0.005} & \multirow{2}{*}{6.811} & \multirow{2}{*}{$0.000^{*}$} \\
\hline & & Medium & 0.333 & 0.006 & 0.321 & 0.345 & & & & \\
\hline & \multirow{2}{*}{ Adhocracy } & Small & 0.221 & 0.005 & 0.211 & 0.232 & \multirow{2}{*}{0.018} & \multirow{2}{*}{0.004} & \multirow{2}{*}{4.726} & \multirow{2}{*}{$0.001^{*}$} \\
\hline & & Medium & 0.203 & 0.005 & 0.193 & 0.213 & & & & \\
\hline & \multirow{2}{*}{ Market } & Small & 0.189 & 0.005 & 0.179 & 0.198 & \multirow{2}{*}{-0.001} & \multirow{2}{*}{0.004} & \multirow{2}{*}{-0.314} & \multirow{2}{*}{1.000} \\
\hline & & Medium & 0.190 & 0.005 & 0.180 & 0.200 & & & & \\
\hline & \multirow{2}{*}{ Hierarchy } & Small & 0.230 & 0.005 & 0.219 & 0.240 & \multirow{2}{*}{-0.036} & \multirow{2}{*}{0.004} & \multirow{2}{*}{-8.885} & \multirow{2}{*}{$0.000^{*}$} \\
\hline & & Medium & 0.266 & 0.006 & 0.255 & 0.277 & & & & \\
\hline \multirow{8}{*}{$31-40$} & \multirow{2}{*}{ Clan } & Small & 0.372 & 0.005 & 0.363 & 0.382 & \multirow{2}{*}{0.032} & \multirow{2}{*}{0.005} & \multirow{2}{*}{6.813} & \multirow{2}{*}{$0.000^{*}$} \\
\hline & & Medium & 0.341 & 0.005 & 0.331 & 0.350 & & & & \\
\hline & Adhocracy & Small & 0.225 & 0.004 & 0.216 & 0.233 & 0.018 & 0.004 & 4730 & $0.001^{*}$ \\
\hline & Adhocracy & Medium & 0.206 & 0.004 & 0.198 & 0.214 & 0.018 & 0.004 & $4 . / 30$ & $0.001^{n}$ \\
\hline & Market & Small & 0.198 & 0.004 & 0.191 & 0.206 & 0001 & 0004 & 0 & 1000 \\
\hline & Market & Medium & 0.200 & 0.004 & 0.192 & 0.207 & -0.001 & 0.004 & -0 & 1.000 \\
\hline & H: & Small & 0.239 & 0.004 & 0.231 & 0.248 & (2007 & 0004 & ( & $0000 x$ \\
\hline & Herarchy & Medium & 0.277 & 0.005 & 0.268 & 0.285 & -0.037 & 0.004 & -8.929 & $0.000^{4}$ \\
\hline & Clan & Small & 0.385 & 0.005 & 0.375 & 0.394 & 0.032 & 0.005 & 6.817 & $0.000^{*}$ \\
\hline & Clan & Medium & 0.353 & 0.005 & 0.344 & 0.362 & 0.032 & 0.005 & 0.817 & $0.000^{n}$ \\
\hline & Adhocract & Small & 0.208 & 0.004 & 0.200 & 0.215 & 0017 & 0004 & 734 & 0001 * \\
\hline 41 & Aanocracy & Medium & 0.190 & 0.004 & 0.183 & 0.197 & & 0.004 & 34 & 0.001 \\
\hline $41-50$ & Marr r & Small & 0.188 & 0.004 & 0.181 & 0.195 & 1 & 0004 & 0314 & 1000 \\
\hline & Market & Medium & 0.189 & 0.004 & 0.182 & 0.196 & 01 & 0.004 & 0.314 & 1.000 \\
\hline & Hirarchy & Small & 0.245 & 0.004 & 0.237 & 0.253 & & 004 & & \\
\hline & Herarchy & Medium & 0.283 & 0.004 & 0.274 & 0.291 & -0.038 & 0.004 & -8.924 & $0.000^{7}$ \\
\hline & Clon & Small & 0.401 & 0.006 & 0.390 & 0.413 & 023 & 0005 & 6708 & 0 OnO* * \\
\hline & Clan & Medium & 0.369 & 0.005 & 0.358 & 0.379 & & 0.005 & 98 & $0.000^{n}$ \\
\hline & Adhorracy & Small & 0.202 & 0.005 & 0.194 & 0.211 & 0.017 & 0004 & & $0 \Omega 01$ * \\
\hline$>50$ & Adhocracy & Medium & 0.185 & 0.004 & 0.177 & 0.193 & 0.017 & 0.004 & 4.702 & $0.001^{\star}$ \\
\hline$>50$ & Market & Small & 0.176 & 0.004 & 0.168 & 0.184 & & 003 & & 0 \\
\hline & Market & Medium & 0.177 & 0.004 & 0.169 & 0.185 & -0.001 & 0.003 & -0.315 & 1.000 \\
\hline & $\mathrm{Hi}_{\mathrm{i}}$ & Small & 0.237 & 0.005 & 0.228 & 0.247 & & 0004 & 8 & م مono* \\
\hline & mera & Medium & 0.274 & 0.005 & 0.265 & 0.284 & $-0.03 /$ & 0.004 & -0.919 & \\
\hline
\end{tabular}

Note: ${ }^{\star} \mathrm{p}<0.05$. 
should be relatively strong, as the participation of employees has important effects on trust, and intimacy between team members, affecting human relations, group unity, cooperation, enterprise efficiency, performance, competitive advantage, economic development, and success of the entire enterprise. The goals of individuals should be in line with corporate goals based on their trust in the business. Equal opportunities should be created for all employees. Strong and clearly defined socially responsible practices should be adopted. The enterprise should perceive employee development as an investment in its sustainable development. Despite the mutual consensus in respondents' opinions, statistical testing confirmed the existence of differences in the opinions of managers in all age categories in clan, adhocracy, and hierarchy corporate culture.

Corporate culture is a continuous, dynamically evolving phenomenon, it does not arise or disappear at a certain moment but requires continual development. Its effective formation and use in business management is based primarily on knowledge and understanding of the meaning of individual corporate rituals and practices. Each enterprise creates its own culture, which has its own specificity, originality, uniqueness, and has important effects on performance, competitive advantage, economic development, and success of the entire enterprise. Nevertheless, many values of the corporate culture of one enterprise overlap with the values of the corporate culture of other companies. Following the results, we can conclude that the preferred level of individual dimensions of corporate culture and preferred type of corporate culture in Slovak SMEs from the industrial sector does not differ. The research hypotheses were confirmed. Managers SMEs of all ages prefer the key values typical of a clan corporate culture to be applied at the strategic level to support the economic development of small and medium-sized enterprises. The results obtained are consistent with previous research (Andrianu, 2020; De Waal et al., 2017), which suggests that clan culture should be applied in companies, focusing on employees, developing human competencies, and strengthening corporate culture by building consensus. As employees are the creators and representatives of corporate culture, it can be concluded that corporate culture positively influences decisionmaking, cooperation, communication, motivation, level of cooperation, problem solving, which has important effects on performance, competitive advantage, economic development, and success of the entire enterprise. Corporate culture also unifies various organizational levels with the enterprise management in their efforts of achieving organizational goals, which become accepted and supported by all employees (Terek Stojanović et al., 2020; Linnenluecke \& Griffiths, 2010). Each entity, made up of individuals and social groups, is therefore governed by a complex cultural system which contributes to its internal coherence. This creates the conditions for its effective functioning with respect for moral, ethical, and ecological aspects, which documents a responsible approach to future generations (Purvis et al., 2019). At the same time, corporate culture gives individuals the opportunity to justify their behavior in relation to the values preferred in the enterprise; managers can use it to support activities that are of interest not only to them but also to employees (Lee \& Kim, 2017; Berrio, 2003).

We consider clan culture to be the most suitable type of corporate culture for Slovak SMEs from the industrial sector because it provides space for employee development, and emphasis on teamwork and communication as it has important effects on support the economic development of small and medium-sized enterprises. Achieving a clan culture is pos- 
sible through employee management, which should be focused on collaboration. Managers should prefer a range of common, relatively consistent values and rules of conduct that are accepted by most employees, which ultimately leads to more efficient management. Employees should be in frequent contact with each other. Members should see themselves as part of one large family that is active and engaged. The work environment should be reminiscent of an extended family, where equal opportunities are created for all employees. Management should take the form of mentoring, with leaders playing the role of advisors or mentors. The glue that holds the organization together is loyalty and mutual trust. Commitment to the business should run high. The long-term benefits of each person's development should be emphasized. Great importance should be attached to cohesion, morality, and the working environment. Success should be understood in terms of the internal environment, care for employees, and long-term investment in human resources. The core values should be rooted in teamwork, participation, communication, and consensus, as confirmed by previous research (Demski et al., 2016; Lizbetinova, 2014). It is precisely the employees who are the "engine" that sets in motion other resources and determines their use (Davidescu et al., 2020). Employees are considered valuable and irreplaceable capital, for example, in terms of achieving long-term goals of a successful enterprise (Salama \& Oláh, 2019; Lim et al., 2016). Qualified employees are important because they bring unique intellectual capital that can influence organizational performance and other firm level outcome (Smaliukiene \& Bekesiene, 2020; Arijs et al., 2018). Also based on the previous research (Ancillo et al., 2021; Davidescu et al., 2019; Vnouckova et al., 2015) employees carry new knowledge, ideas, experience, and skills, thus contributing to increasing not only the performance, competitive advantage, economic development, and success of the entire enterprise but also economic development of the small and medium-sized enterprises.

\section{Conclusions}

The presented research on corporate culture examined the key values that should be applied in SMEs from the industrial sector in Slovakia at a strategic level to support the economic development of small and medium-sized enterprises. As managers have a direct impact on the creation of corporate culture, their preferences regarding corporate culture are examined. Their main task is to be aware of the complexity and longevity of the process of creating a corporate culture. All managerial decisions related to corporate culture should be thought through, conceptual, and aligned with the current situation in the enterprise. The results of the research show that SMEs managers of all ages prefer the key values typical of a clan culture to be applied, which suggests that companies should be seen as very personal places that resemble a multi-member family. Employee management should focus on teamwork and collaboration. Employees should be united by loyalty and mutual trust. Business strategies should focus on human development, high trust, openness, and inertia in cooperation. Business success should be based on human resource development and teamwork. We identify with the results. We recommend that managers apply the key values typical of the clan culture in management, because it emphasizes employees who are of strategic importance for the enterprise. 


\section{Acknowledgements}

This work was supported by VEGA 1/0161/21 Dependence of the type of corporate culture on the industries of Slovak enterprises and selected socio-demographic factors, VEGA 1/0737/20 Consumer literacy and intergenerational changes in consumer preferences when purchasing Slovak products, KEGA 005TU Z-4/2020 Economics, management and enterprising in wood industry companies - University textbook with visualization support in virtual space, and APVV-20-0004 The effect of an increase in the anthropometric measurements of the Slovak population on the functional properties of furniture and the business processes.

\section{Funding}

This work was supported by the VEGA under Grant [1/0161/21].

\section{Author contributions}

SL, AM and MH conceived the study and were responsible for the design and development of the data analysis. SL, AM and $\mathrm{MH}$ were responsible for data collection and analysis. SL, $\mathrm{AM}$ and $\mathrm{MH}$ were responsible for data interpretation. SL, AM and $\mathrm{MH}$ wrote the first draft of the article.

\section{Disclosure statement}

Authors declare no financial, professional, or personal interests from other parties.

\section{References}

Abdi, K., Mardani, A., Senin, A. A., Tupenaite, L., Naimaviciene, J., Kanapeckiene, L., \& Kutut, V. (2018). The effect of knowledge management, organizational culture and organizational learning on innovation in automotive industry. Journal of Business Economics and Management, 19(1), 1-19. https://doi.org/10.3846/jbem.2018.1477

Al Issa, H. E. (2019). Organisational culture in public universities: Empirical evidence. Asian Journal of Business and Accounting, 12(1). https://doi.org/10.22452/ajba.vol12no1.2

Ancillo, A. D., Nunez, M. T. D., \& Gavrila, S. G. (2021). Workplace change within the COVID-19 context: a grounded theory approach. Economic Research-Ekonomska Istrazivanja, 34(1), 2297-2316. https://doi.org/10.1080/1331677X.2020.1862689

Andrianu, A. B. (2020). Resilient organizational culture: Cluj-Napoca case study. Eastern Journal of European Studies, 11(1), 335-357.

Anguelov, K., \& Angelova, M. (2021). Home office effects on the motivation of ict companies' employees. Entrepreneurship and Sustainability Issues, 8(4), 10-28. https://doi.org/10.9770/jesi.2021.8.4(1)

Arijs, D., Botero, I. C., Michiels, A., \& Molly, V. (2018). Family business employer brand: Understanding applicants' perceptions and their job pursuit intentions with samples from the US and Belgium. Journal of Family Business Strategy, 9(3), 180-191. https://doi.org/10.1016/j.jfbs.2018.08.005

Aziz, A. R. Z., \& Hiroshi, M. (2014, October). A comparative study of culture and performance in TQM, ISO and Non-TQM firms. Paper presented at the International Conference on Quality, Tokyo, Japan. 
Belias, D., Koustelios, A., Vairaktarakis, G., \& Sdrolias, L. (2015). Organizational culture and job satisfaction of Greek banking institutions. Procedia - Social and Behavioral Sciences, 175, 314-323. https://doi.org/10.1016/j.sbspro.2015.01.1206

Berrio, A. A. (2003). An organizational culture assessment using the competing values framework: A profile of Ohio state university extension. Journal of Extension, 41(2).

Caliskan, A., \& Zhu, C. (2019). Organizational culture type in Turkish universities using OCAI: Perceptions of students. Journal of Ecudation Culture and Society, 10(2), 270-292. https://doi.org/10.15503/jecs20192.270.292

Cameron, K. S., \& Quinn, R. E. (1999). Diagnosing and Changing organizational culture based on the competing values framework. Addison - Wesley, Reading, UK.

Chen, S. H., Xu, L. L., \& Jebran, K. (2021). The effect of Confucian culture on corporate tax avoidance: evidence from China. Economic Research-Ekonomska Istrazivanja, 34(1), 1342-1365. https://doi.org/10.1080/1331677X.2020.1825105

Davidescu, A. A. M., Roman, M., Strat, V. A., \& Mosora, M. (2019). Regional sustainability, individual expectations and work motivation: A multilevel analysis. Sustainability, 11(12), 3331. https://doi.org/10.3390/su11123331

Davidescu, A. A., Apostu, S. A., Paul, A., \& Casuneanu, I. (2020) Work flexibility, job satisfaction, and job performance among romanian employees-Implications for sustainable human resource management. Sustainability, 12(15), 6086. https://doi.org/10.3390/su12156086

De Waal, A., Linde, P., \& Broekhuizen, M. (2017). Do different generations look differently at high performance organizations? Journal of Strategy and Management, 10(1), 86-101. https://doi.org/10.1108/JSMA-10-2015-0083

Deal, T., \& Kennedy, A. (1982). Corporate cultures. Punguin books.

Debski, M., Cieciora, M., Pietrzak, P., \& Bolkunow, W. (2020). Organizational culture in public and non-public higher education institutions in Poland: A study based on Cameron and Quinn's model. Human Systems Management, 39(3), 345-355. https://doi.org/10.3233/HSM-190831

Demski, D., Van Ackeren, I., \& Clausen, M. (2016). The interrelation of school culture and evidence-based practice - Findings of a survey using the Organizational Culture Assessment Instrument. Journal for Educational Research Online-Jero, 8(3), 39-58.

Denison, D. R., \& Spreitzer, G. M. (1991). Organizational culture and organizational development: A competing values approach. Research in Organizational Change and Development, 5, 1-21.

Diedrich, M. (2017). Adapting a corporate culture to the changing circumstances - cultural change through social media. Marketing Science \& Inspirations, 12(1), 2-9.

Dostiyarova, A. (2016). Students' perception of organizational culture at Kimep Universtiy based on OCAI instrument. Bulletin of the National Academy of Sciences of the Republic of Kazakhstan, 3, 89-94.

Fernandez, R., \& Fogli, A. (2009). Culture: An empirical investigation of beliefs, work, and fertility. American Economic Journal: Macroeconomics, 1(1), 146-177. https://doi.org/10.1257/mac.1.1.146

Guiso, L., Sapienza, P., \& Zingales, L. (2015). The value of corporate culture. Journal of Financial Economics, 117(1), 60-76. https://doi.org/10.1016/j.jfineco.2014.05.010

Ha, V. D. (2020). Impact of organizational culture on the accounting information system and operational performance of small and medium sized enterprises in Ho Chi Minh City. Journal of Asian Finance Economics and Business, 7(2), 301-308. https://doi.org/10.13106/jafeb.2020.vol7.no2.301

Handy, C. (1985). Unterstanding organizations. Penguin Books.

Harrison, R. (1972). How to develop your organization. Harvard Business Review, 118-128.

Hartnell, C. A., Ou, A. Y., \& Kinicki, A. (2011). Organizational culture and organizational effectiveness: A meta-analytic investigation of the competing values framework's theoretical suppositions. Journal of Applied Psychology, 96(4), 677-694. https://doi.org/10.1037/a0021987 
Hedvicakova, M., \& Kral, M. (2021). Performance evaluation framework under the influence of industry 4.0: The case of the Czech manufacturing industry. E \& M Ekonomie a Management, 24(1), 118-134. https://doi.org/10.15240/tul/001/2021-1-008

Ibarra-Michel, J. P., Velarde-Valdez, M., Olmos-Martinez, E., \& Santillan-Nunez, M. A. (2019). Organizational culture assessment of sustainable hotel companies in Mazatlan; four case studies. Investigaciones Turisticas, 17, 71-102. https://doi.org/10.14198/INTURI2019.17.04

Jaeger, M., \& Adair, D. (2013). Organisational culture of construction project managers in the GCC countries. Engineering, Construction and Architectural Management, 20(5), 461-473. https://doi.org/10.1108/ECAM-01-2012-0004

Kets De Vries, M. F. R., \& Miller, D. (1984). The neurotic organization: Diagnosing and changing counterproductive styles of management. Jossey-Bass, San Francisco, USA.

Kotter, J. P., \& Heskett, J. L. (2011). Corporate culture and performance. The Free Press, New York, USA.

Kraśnicka, T., Glod, W., \& Wronka-Pośpiech, M. (2018). Management innovation, pro-innovation organisational culture and enterprise performance: Testing the mediation effect. Review of Managerial Science, 12, 737-769.

Lee, M., \& Kim, H. (2017). Exploring the organizational culture's moderating role of effects of corporate social responsibility (CSR) on firm performance: Focused on corporate contributions in Korea. Sustainability, 9(10), 1883. https://doi.org/10.3390/su9101883

Lim, B. T. H., Wang, Z., \& Oo, B. L. (2016). Change management for sustainable competitive advantages: The roles of organisational culture and employees in the Chinese construction firms. International Journal of Sustainable Building Technology and Urban Development, 7(3-4), 230-236. https://doi.org/10.1080/2093761X.2017.1302842

Linnenluecke, M. K., \& Griffiths, A. (2010). Corporate sustainability and organizational culture. Journal of World Business, 45(4), 357-366. https://doi.org/10.1016/j.jwb.2009.08.006

Lizbetinova, L. (2014). The quality of communication in the context of regional development. Deturope-The Central European Journal of Regional Development and Tourism, 6(3), 22-38.

Lobos, K., Malatek, V., \& Szewczyk, M. (2020). Management practices in area of human resources and monitoring results as determinants of SME's success in Poland and the Czech Republic. E \& $M$ Ekonomie a Management, 23(2), 114-125. https://doi.org/10.15240/tul/001/2020-2-008

Lorincova, S., Hitka, M., \& Balazova, Z. (2016). Corporate culture in Slovak enterprises as a factor of HRM quality - case study. International Journal for Quality Research, 10(4), 719-732. https://doi.org/10.18421/IJQR10.04-04

Miles, R., Snow, C. C., Meyer, A. D., \& Coleman, H. J. Jr. (1978). Organization strategy, structure, and process. The Academy of Management Review, 3(3), 546-562.

Mohelska, H., \& Sokolova, M. (2018). Management approaches for industry 4.0-the organizational culture perspective. Technological and Economic Development of Economy, 24(6), 2225-2240. https://doi.org/10.3846/tede.2018.6397

Naranjo-Valencia, J. C., Jiménez-Jiménez, D., \& Sanz-Valle, R. (2016). Studying the links between organizational culture, innovation, and performance in Spanish companies. Revista Latinoamericana de Psicología, 48, 30-41. https://doi.org/10.1016/j.rlp.2015.09.009

O'Reilly, C. A., \& Chatman, J. A. (1996). Culture as social control: Corporations, culture and commitment. In B. M. Staw and L. L. Cummings (Ed.), Research in organizational behavior (pp. 157-200). JAI Press.

Purvis, B., Mao, Y., \& Robinson, D. (2019). Three pillars of sustainability: in search of conceptual origins. Sustainability Science, 14, 681-695. https://doi.org/10.1007/s11625-018-0627-5

Quinn, R. E., \& Rohrbaugh, J. (1983). A spatial model of effectiveness criteria: Toward a competing values approach to organizational analysis. Management Science, 29, 363-377.

https://doi.org/10.1287/mnsc.29.3.363 
Rezaei, G., Mardani, A., Senin, A. A., Wong, K. Y., Sadeghi, L., Najmi, M., \& Shaharoun, A. M. (2016). Relationship between culture of excellence and organisational performance in Iranian manufacturing companies. Total Quality Management and Business Excellence, 29(1-2), 94-115. https://doi.org/10.1080/14783363.2016.1168692

Salama, A., \& Oláh, J. (2019). Key factors affecting unemployment in the Arab world. Central European Journal of Labour Law and Personnel Management, 2(2), 60-72. https://doi.org/10.33382/cejllpm.2019.03.05

Smaliukiene, R., \& Bekesiene, S. (2020). Towards sustainable human resources: How generational differences impact subjective wellbeing in the military? Sustainability, 12(23), 10016. https://doi.org/10.3390/su122310016

Soewarno, N., \& Tjahjadi, B. (2020). Eco-oriented culture and financial performance: Roles of innovation strategy and eco-oriented continuous improvement in manufacturing state-owned enterprises, Indonesia. Entrepreneurship and Sustainability Issues, 8(2), 341-359.

https://doi.org/10.9770/jesi.2020.8.2(20)

Sonnenfeld, J. A. (1988). The hero's farewell: What happens when CEOs refire. Oxford University Press.

Stachová, K., Stacho, Z., \& Pajtinková Bartáková, G. (2015). Influencing organisational culture by means of employee remuneration. Business: Theory and Practice, 16, 264-270. https://doi.org/10.3846/btp.2015.492

Statistical Office of the Slovak Republic. (2018). Štatistická ročenka Slovenskej republiky (Statistical Yearbook of the Slovak Republic). VEDA.

Teräväinen, V. J., \& Junnonen, J. M. (2019). The promoters and the barriers for organizational culture change in a Finnish construction company. Construction Innovation - England, 19(4), 672-688. https://doi.org/10.1108/CI-04-2019-0029

Teräväinen, V. J., Junnonen, J., \& Ali-Löytty, S. (2018). Organizational culture: Case of the finnish construction industry. Construction Economics and Building, 18(1), 48-69. https://doi.org/10.5130/AJCEB.v18i1.5770

Terek Stojanović, E., Vlahović, M., Nikolić, M., Mitić, S., \& Jovanović, Z. (2020). The relationship between organizational culture and public relations in business organizations. Journal of Business Economics and Management, 21(6), 1628-1645. https://doi.org/10.3846/jbem.2020.13377

Tian, X. L., Niu, M. L., Zhang, W. K., Li, L. H., \& Herrera-Viedma, E. (2021). A novel todim based on prospect theory to select green supplier with q-rung orthopair fuzzy set. Technological and Economic Development of Economy, 27(2), 284-310. https://doi.org/10.3846/tede.2021.12736

Van Huy, N., Thu, N. T. H., Anh, N. L., Au, N. T. H., Phuong, N. T., Cham, N. T., \& Minh, P. D. (2020). The validation of organisational culture assessment instrument in healthcare setting: Results from a cross-sectional study in Vietnam. BMC Public Health, 20(1), 316. https://doi.org/10.1186/s12889-020-8372-y

Vlaicu, F. L., Neagoe, A., Țîru, L. G., \& Otovescu, A. (2019). The organizational culture of a major social work institution in Romania: A sociological analysis. Sustainability, 11(13), 3587. https://doi.org/10.3390/su11133587

Vnouckova, L., Urbancova, H., \& Smolova, H. (2015). Approaches to employee development in Czech organisations. Journal on Efficiency and Responsibility in Education and Science, 8(1), 1-7. https://doi.org/10.7160/eriesj.2015.080101

Vukasovic, D., Gligovic, D., Terzic, S., Stevic, Z., \& Macura, P. (2021). Novel fuzzy mcdm model for inventory management in order to increase business efficiency. Technological and Economic Development of Economy, 27(2), 386-458. https://doi.org/10.3846/tede.2021.14427 